\title{
Augmenting visual design: Designing the changing classroom
}

E-Learning and Digital Media

(C) The Author(s) 2018

Reprints and permissions: sagepub.co.uk/journalsPermissions.nav DOI: $10.1177 / 2042753018773769$ journals.sagepub.com/home/ldm

@SAGE

\section{David Sinfield and Thomas Cochrane (D)}

Auckland University of Technology, New Zealand

\begin{abstract}
Art and design undergraduate educational programmes such as Graphic Design studies are based upon best practice within the Graphic Design industry. Thus, the classroom environment is designed to mirror a typical design studio environment. However, traditional design studio interaction and collaboration are undergoing rapid transformation in practice triggered by an increasingly global digitally networked professional environment. In response, this paper outlines our journey of redesigning an undergraduate graphic design curriculum to enable students to engage beyond the context of the classroom to a potentially global audience. Over two redesign iterations Visual Communication Design students explored new technologies including mobile augmented reality and virtual reality to enhance the reach and impact of their portfolios of work. Using the concept of Visual Poetry and a combination of typography and moving image, the students created a range of art pieces inspired by a specific location, and shared these via an ecology of resources chosen to digitally augment their work and facilitate the production of student eportfolios. The goal of the curriculum redesign is to broaden students' educational experiences beyond the confines of the traditional studio based classroom to include wider community outreach and participation within an increasingly global environment.
\end{abstract}

\section{Keywords}

Curriculum redesign, design-based research, mobile augmented reality, mobile virtual reality

\section{Introduction}

The Bachelor of Design Communication is a three-year undergraduate degree programme based in Manukau, South Auckland, New Zealand. At the Manukau campus, students major in Visual Communication design, under the broad umbrella of Graphic Design. During their three years of study, students engage in the typical communication design

\section{Corresponding author:}

Thomas Cochrane, Auckland University of Technology, 56 Wellesley St, Auckland II42, New Zealand. Email: Thomas.Cochrane@aut.ac.nz 
projects such as logo design, branding, publication construction, poster design and so on all the elements normally associated with the graphic design industry. However, Graphic Design is a discipline that is undergoing major changes with its associated technologies, and while the underlying design principles may remain fundamentally intact, new digital technologies and publishing mediums provide new challenges (Gibson, 2008).

The pedagogic approach to Graphic Design discipline is mainly based on the typical design studio environment, whereby individuals or small teams will work together on a specific brief while overseen by the creative director, in this case the teacher of the students. This method of engaging in a studio-like environment has proven to be effective both as student satisfaction and indeed preparation for entering the design industry. The students are given a project brief much like they would be in the actual working environment. The students go through the entire process of research and design concepts through to the finished product as assigned in the project brief. The classroom would have the set-up much like a conventional studio with a dedicated space and traditional equipment. The students are engaged in the practical work and fully participate in all teacher-student and student-student discussions much like the design industry. They would go through the design processes with formative discussions and teacher-student and peer critiquing.

However, while this process is successful, it follows a traditional model of the graphic design industry and does not reflect newly emerging modes of global networking and new technologies that are impacting the industry. In short, we argue that higher education should prepare students for the future of the industry into which they will enter upon graduation and beyond. As Barnett (2012) argues, we need to be giving our students the skills to navigate a rapidly changing world. However recent student surveys from the UK, USA, NZ, and Europe, all highlight that there is a disconnect between the integration of new technologies in students' social lives and that used in formal education (Beetham and White, 2014; Dahlstrom et al., 2015; Frielick and Whitehead, 2017; OECD, 2015). The modern-day student is potentially equipped with a wide variety of devices such as smart phones, laptops, tablets, and gaming devices. In particular, graphic design students communicate amongst their peers using a variety of online and social media platforms, and continually update their online profiles while sharing new designs and images they have created. This has led many educational institutions to explore the use of student-owned devices in the curriculum (Parsons, 2013; Santos, 2013; Sweeney, 2012), a strategy labelled BYOD (Bring Your Own Device). However, BYOD educational strategies have many implications, as highlighted by Traxler (2010), "If institutions chose to work with student-owned devices, they would increase their capacity to deliver inclusion with innovation but would find the transformation challenging" (p. 3). Therefore a successful BYOD strategy that matches student learning environments with new and emerging graduate outcomes requires a carefully redesigned curriculum (Cochrane, et al., 2014).

With these issues in mind we chose to explore the impact of the two emerging technologies of mobile Augmented Reality (AR) and Virtual Reality (VR) within the graphic design curriculum. Alongside the ubiquity of mobile devices these two technologies are expected to impact many visual design industries (Cook, 2016; Lalwani, 2015; Munnerley et al., 2014; Somaiya, 2015; Yang, 2015). This paper introduces the first stages of a design-based research project, exploring collaborative curriculum redesign involving the scoping and prototyping of the integration of student-generated mobile AR and VR projects within the second and third year undergraduate graphic design curriculum. Firstly, we explore the literature that informs our redesign process, beginning with collaborative curriculum 
design methodologies, an overview of how mobile augmented reality and virtual reality are impacting higher education, and an overview of new pedagogical strategies that guide and frame our curriculum redesign.

\section{Literature review}

The role of the graphic designer is increasingly changing and requires adaptation to new methods and technologies (Bower et al., 2014). As educators, we need to design learning environments that critically engage students with the issues and practicalities of new technologies in their discipline contexts. In the following sections, we explore the literature that informed our design process.

\section{Collaborative curriculum design}

A scholarly advocate for the redesign of higher education curricula Laurillard (2012), argues that curriculum design is a complex process that involves a wide variety of skills that are best achieved within curriculum design teams, involving the collaboration of curriculum experts, educational technologists, and educational theorists. Additionally, Laurillard argues that curriculum design should be regarded as a design science rather than conducted ad hoc or as a quick reaction to a variety of pressures (Laurillard, 2001; Laurillard et al., 2013). Laurillard advocates that technology can be used as a tool for pedagogical innovation when designed to integrate within the curriculum appropriately (Laurillard, 2008). Laurillard's call for collaborative curriculum design teams is echoed by many recent educational theorists and practitioners (Balsamo, 2011; Buchem et al., 2012; Emin-Martinez et al., 2014; Garnett and Ecclesfield, 2008; Weaver et al., 2012).

\section{Design-based research}

In design education, theory development is inextricably linked to practice. The study of communication design is a complex interdisciplinary field of knowledge, and draws on several theoretical perspectives and research paradigms to build understandings and meanings (Wang and Hannafin, 2005: 5). To explore the fundamental synergy between theory and practice we chose a design-based research (Collins, 1999) approach. Barab and Squaire (2004) argue that DBR focuses on "understanding the messiness of real-world practice, with context being a core part of the story and not an extraneous variable to be trivialized" (p. 3). Similarly, Cook and Santos (2016) argue DBR is one way to deal with the inherent messiness of mobile learning, where learning can occur outside of the boundaries of the formal classroom using students' own devices anytime anywhere, and beyond the direct input of a teacher. McKenney and Reeves (2012) outline four stages in DBR applied to designing learning environments, illustrated in Figure 1, including informed exploration, prototype learning design and implementation, evaluation, and refined learning design.

The fourth stage of DBR involves wider evaluation and feedback, which in our case we implement via peer review and feedback on the publication of our redesign process. The goal of design-based research is the identification and refinement of transferable design principles that can potentially be applied to other educational contexts. 


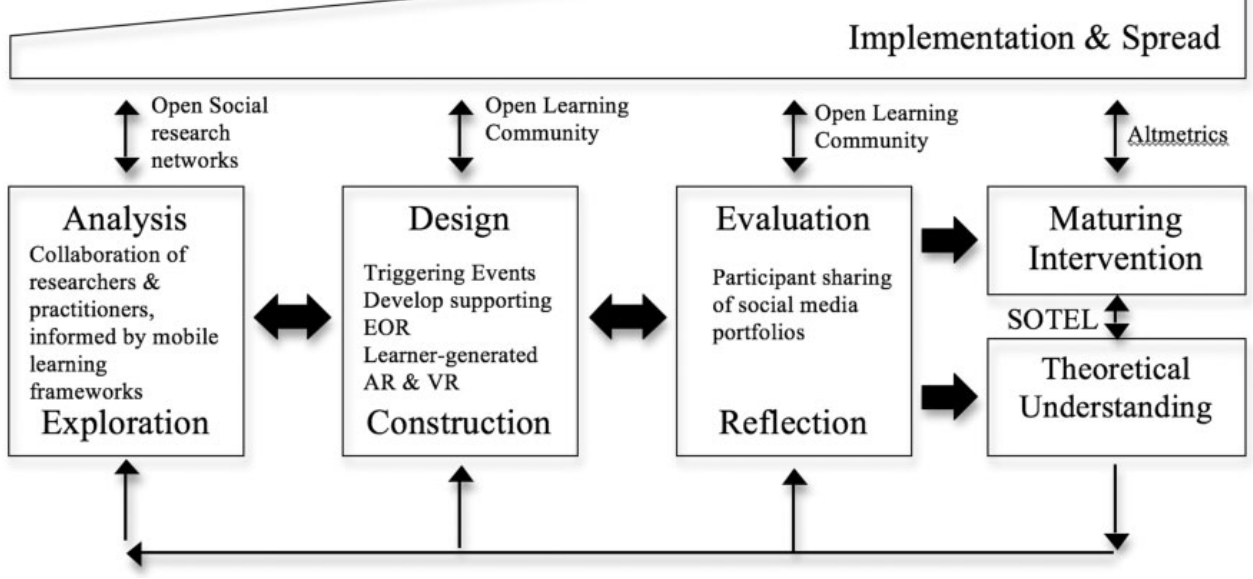

Figure I. Four stages of DBR.

\section{Integrating new technologies: Virtual and augmented reality}

AR and VR (Augmented Reality and Virtual Reality) are two emergent technologies currently being used within specialised industries such as aerospace, automotive, medical military, and scientific arenas where the real environment can either be augmented or simulated safely and at lower costs than previously possible. These technologies are now becoming widely accessible and economically viable via mobile devices such as smartphones and costeffective head mounted displays (Cochrane, 2016). Through the impact of phenomena such as Pokemon Go, mobile AR has begun to have wide uptake across the globe. Mobile AR provides the user with the ability to overlay the real word with images, text, audio and moving image, superimposed on the actual physical space as seen through a smartphones camera and screen (Cook, 2016). In contrast, virtual reality (VR) is a perception of being physically present in a nonphysical world (Ott and Freina, 2015). For example, 3D virtual reality HMD (Head Mounted Device) can be used to explore a 360-degree view of a panorama or 360 degree video, which makes the user experience more immersive than looking at a flat image on a computer screen (Kidd and Crompton, 2016). Beyond play back of immersive content, we have previously argued that integrating user-generated mobile AR and VR in learning environments is a powerful way to create authentic learning experiences (Cochrane, 2016; Cochrane et al., 2016). Mobile augmented reality (mobile AR) and mobile VR has undergone rapid development from a reliance upon specialised professional production teams to enabling user generated content via freely available platforms such as Google Streetview and 360-degree video via YouTube (Cook, 2010; Delello et al., 2015; FitzGerald et al., 2013). Thus mobile AR and VR now provide opportunities for studentgenerated contexts (Cochrane et al., 2015). For example, studies in enhancing Graphic Design with mobile technologies have shown the potential to link authentic contexts with student learning and student exhibitions (Cochrane et al., 2014; Sinfield, 2013). Therefore, with the growing ubiquity of mobile device ownership within not only the student 
population but also the general community populace (International Telecommunication Union, 2015) there is an opportunity to reach wider audiences for experiencing student artwork via mobile augmentation and distribution of virtual student exhibitions (Kidd and Crompton, 2016).

\section{Exploring new pedagogical strategies}

Integrating new technologies into the curriculum needs to be based upon learning theories that support the development of new pedagogical strategies. We chose to base our curriculum redesign upon pedagogies that support creativity, specifically the intersection between social constructivism (Bandura, 1986; Bruner, 1966) that emphasises collaboration and learning from more expert peers, authentic learning (Herrington and Herrington, 2006) that focuses learning environments on real world scenarios, and Heutagogy or studentdetermined learning (Hase and Kenyon, 2007). Heutagogy is a relatively new term that defines learning as building students' capacity to navigate novel and unknown contexts.

We need to explore new pedagogies when integrating new technologies into the curriculum in order to move beyond simply replicating current teaching and learning practice. Puentedura (2011) argues that we need to move beyond substitution of current strategies using new technologies, and move towards utilising new technologies to enable learning experiences that were either impossible or impractical via prior technologies. A pedagogy first approach will utilise technology as an enabler of new learning environments (Laurillard, 2012). One such strategy is Rhizomatic Learning (Cormier, 2008). Rhizomatic learning decentralises learning from what the teacher does and directs, to what the students explore and do, whereby the role of the teacher moves from that of content delivery to becoming the designer of triggering events to facilitate student creativity and collaboration. These triggering events are supported by an appropriate choice of technologies that Cormier terms an ecology of resources. The idea of a supporting ecology of resources (or technologies) is based upon Luckin's (2008) concept of a learner centred ecology of resources. Extending this concept and drawing upon Pachler et al.'s (2010) socio-cultural ecological concept, Cook et al. (2013) argue that mobile social media can bridge the socio-cultural milieus of everyday life and education. Thus we based our ecology of resources upon a collage of mobile social media, as outlined in the methodology section of this paper.

In summary, a search of the literature led us to base our curriculum redesign project on an explicit collaboration between graphic design lecturers and educational technology researchers, using a design-based research methodology, to ensure that the curriculum redesign is both informed by learning theory while also anchored in the specific discipline contexts most relevant to our student graduate outcomes. In the following sections, we outline our project methodology, and follow this with an overview of two iterations of curriculum redesign.

\section{Methodology}

Informed by our review of the literature, the curriculum redesign project methodology was guided by using Design-Based Research as a foundational methodology (Cochrane et al., 2016), as described in the literature review. This involved a collaboration between the course lecturers and education researchers following the four stages of DBR: informed exploration, 
initial prototyping of new learning activities, evaluation of the impact of the new activities and assessments, followed by redesign and further prototyping and implementation within the curriculum. We formed a community of practice comprised of the course lecturers and an educational technologist and began meeting weekly throughout the first semester of 2016 to explore new pedagogical strategies and design new learning activities and assessments. The lecturers were supplied with smartphones and tablets, and participated within a cMOOC as a wider collaborative pedagogical network. The initial exploration stage of the project, introduced in 2016 was informed by a previously developed Mobile Social Media Framework (Cochrane et al., 2015). This framework maps core elements of new pedagogies to the development of student eportfolios made up of a collage of mobile social media platforms. The second and following stages involved prototyping of a redesigned year 2 curriculum in 2016 followed by evaluation (Steagall et al., 2016), then a subsequent prototyping and evaluation of a redesigned year 3 curriculum in 2016 (Sinfield et al., 2017). The prototyping involved the development of student projects designed using an Atelier (Brown, 2006) model and Rhizomatic Learning (Cormier, 2008), supported via the development of an Ecology of Resources (EOR) that included five main elements (Figure 2), with each element mediated by the choice of one or more appropriate mobile social media technologies.

Embedded within the project was the integration of reflective practice via the scholarship of technology enhanced learning (SOTEL), and thus we framed the curriculum redesign around the following two research questions.

\section{Research questions}

Our research questions were:

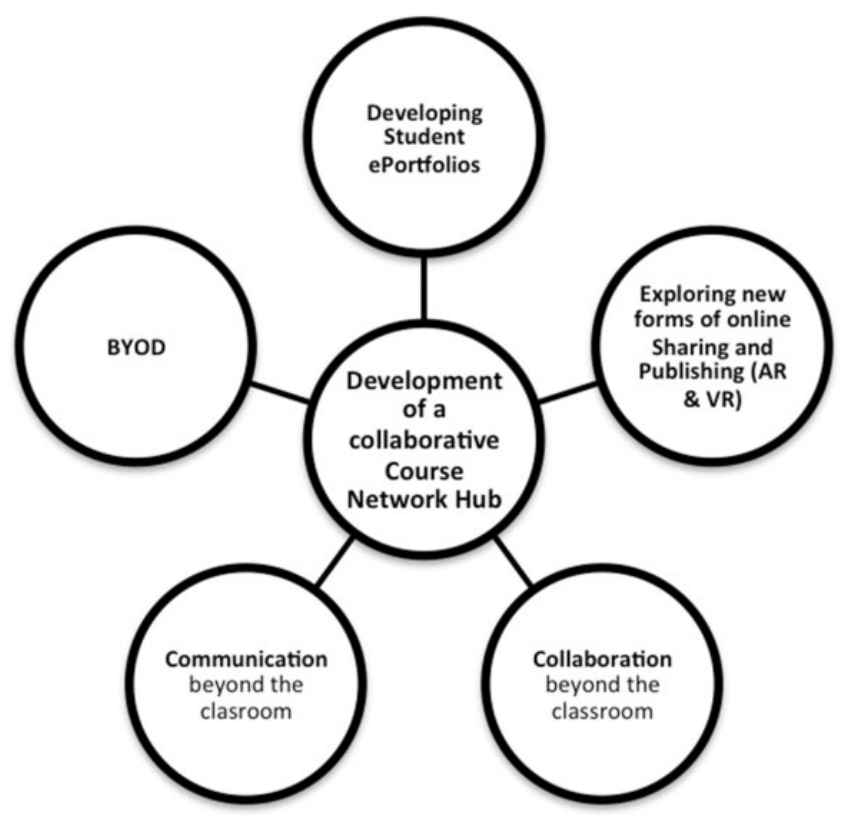

Figure 2. Project ecology of resources model. 
- How can we design learning experiences that motivate graphic design students to critically explore new and emerging technologies, for example mobile augmented reality and virtual reality?

- What assessment strategies can we use to highlight the potential of mobile AR and VR for showcasing student work to a much wider community audience beyond the physical classroom?

To this end, we investigated how augmented reality and virtual reality can extend the boundaries of the classroom to locate and share students' work within a global environment, and in doing so this paper explores the integration of a DBR methodology to guide the curriculum redesign.

\section{Ethics}

To enable this research project to be published using student examples of work with their permission, ethics approval from Auckland University of Technology was applied for and granted. This study focused on the outcomes of a student design project as part of a new curriculum initiative that employs Augmented Reality and Virtual Reality technologies to extend the theoretical boundaries of the classroom beyond its physical limits. Student participation consent forms and research information sheets were supplied to the participating students via an independent third party. An initial anonymous questionnaire was used at the start of the semester to gather student prior experiences, and one at the end of the semester to gather feedback on their experience from the project. In addition to the project surveys, examples of the student work (portfolios) from this project were also curated. This took place at the end of the semester after the student's work had been completed and final grades presented at the faculty exam board of studies.

\section{Participants}

Students from the 2016 second year cohort and the third year 2017 cohort of the Visual Communications Design programme were invited to participate in this research. The campus is located in the area of Manukau, South Auckland, New Zealand. The region of Manukau has a complex multicultural community comprising mainly Mãori and Pacifika people with a growing number of European and Asians demographics. This is also reflected on the student demographics within the programme. Student participation in the research part of the curriculum redesign was voluntary. Participation did not require any extra time from the students apart from completing the associated questionnaires that took approximately 10 minutes to complete.

\section{Curriculum redesign project}

\section{Curriculum redesign stage I: The 2016 student project}

The participants in the first 2016 iteration of our project included the second year of a threeyear Visual Design degree cohort, with a total of 23 students. Students were asked to bring their own devices and use the built-in geolocation sensors (GPS and compass) to choose a specific geographic location to become the focal point for their work. Using the theory of concrete poetry ${ }^{1}$ and design practice (Hollis, 2001; Munari, 2008) each student had to 
choose a published piece or write their own poem that reflected their chosen place within Manukau. The assessment brief was redesigned to extend a traditional typographical design brief where students were required to convey the poem in typographically form in a sympathetic manner to their chosen area. Students explored simple forms of augmented reality to add viewer interactivity to their work via digital and geolocation data to what would previously have been simply paper-based projects displayed in a physical exhibition. By presenting their work in an interactive way students provided a gift or $\mathrm{Koha}^{2}$ for the local community of Manukau, South Auckland.

Using this region for inspiration the students chose a location inside the Manukau region that had a significant meaning in terms of culture, a specific event or memory for them. Equally this could have a diverse connection for familiarity, happiness, loneliness, or indeed sadness but would have to reflect on their poem. The starting point of the project meant the students had to immerse themselves into the surroundings, its community, its cultural aspects and its identity. The immersion process draws from situated cognition, where the mind and body are not two separated entities but a continuous substance that incorporates reason and emotion in time and space. This thinking draws upon Spinoza and Boyle's (1959) proposal that, "the mind is united to the body because the body is the object of the mind" (p. 59).

By walking and observing the area, they had to investigate all possible aspects and to collect a variety of data that could be used in a qualitative research to define their design concepts. In this manner, the students utilised their smartphones to gather imagery and video with embedded geolocation data to reflect on the signs and symbols from their chosen area, and to establish a method that allowed them to create an immersive experience related to the meaning of their area.

In redesigning the way students interacted and collaborated on their projects we augmented the traditional design studio learning environment with the following ecology of resources made up of a collage of social media and mobile AR tools in 2016:

- Student Wordpress blogs as reflective workbooks/journals, curated via Flipboard for formative feedback

- Student-generated Vine videos to introduce their work

- Student-generated Google Street view 360 panoramas of their selected geographic context

- A collaborative shared Google Map as a hub for linking student project artefacts

- Wikitude to create and share a mobile AR version of the project map

The relationship to our ecology of resources model is illustrated in Figure 3.

In the traditional form of graphic design, the students' work comprised of a set of three visual elements (a series of posters, documented publication, 3D object) with the visual representation being presented in a less than conventional graphic design manner that of an augmented manner in a virtual arena. Within our programme (Visual Communication Design) based in Manukau, we are focused on the production of design content and messages being delivered through different mediums, to communicate and to produce meaning within the design product. In other words, designers produce images, texts audio, moving image, and are always looking for new vehicles to deliver their designs and their messages.

The process of AR allows the designer to deliver messages in a geographically and interactive modes. By using the concept AR and Google Maps to extend the geographic area of 


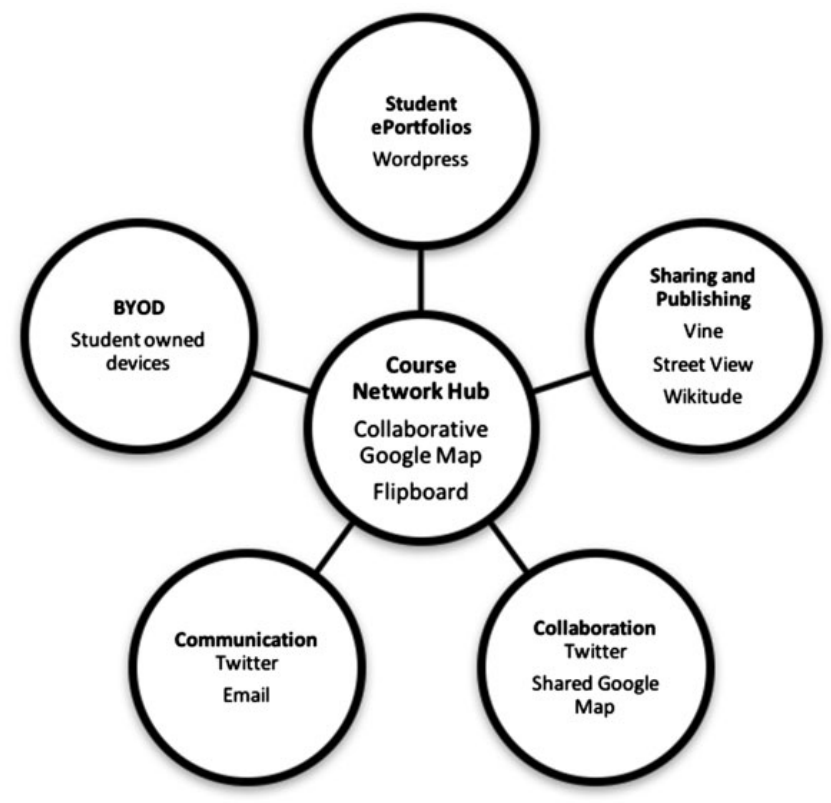

Figure 3. 2016 Ecology of resources.

Manukau, within the virtual world using a varied multimedia content, including videos, still images and design concepts, thus making the locations much more appealing and interesting. From this perspective, students located their area by 'pinning' on the map their location within Google Maps and by activating Google Street View the content could be used. Because the locations on the maps are published in the public arena, a greater understanding of the area and the community is greater understood. Further content by the student was added in the form of panoramas of their chosen place making a richer visual content. The students were asked to take panoramic images of their chosen area and upload them to Google Street View using their own devices. This was a collaborative process with all the students in the class sharing their images and their visual content onto a shared Google Map. The map received 313 views in only a few weeks, with 531 views at the date of writing (Figure 4).

Figure 2 shows 377 views within a few days of creation, indicating significant community engagement beyond the 15 undergraduate students. We also introduced students to other mobile application software such as Wikitude to create a mobile AR 'world', recording and sharing a virtual tour of their work.

The 2016 project represents the first two stages of our DBR research that included an exploration of the literature and our initial prototype curriculum redesign for the second year of the course. The third stage is represented by our curriculum redesign of the following third year curriculum in 2017.

\section{Curriculum redesign stage 2: The 2017 student project}

In 2017, we built upon our first augmented classroom project with the same 2016 second year student cohort, then third year students. This refined what we explored in 2016 in 


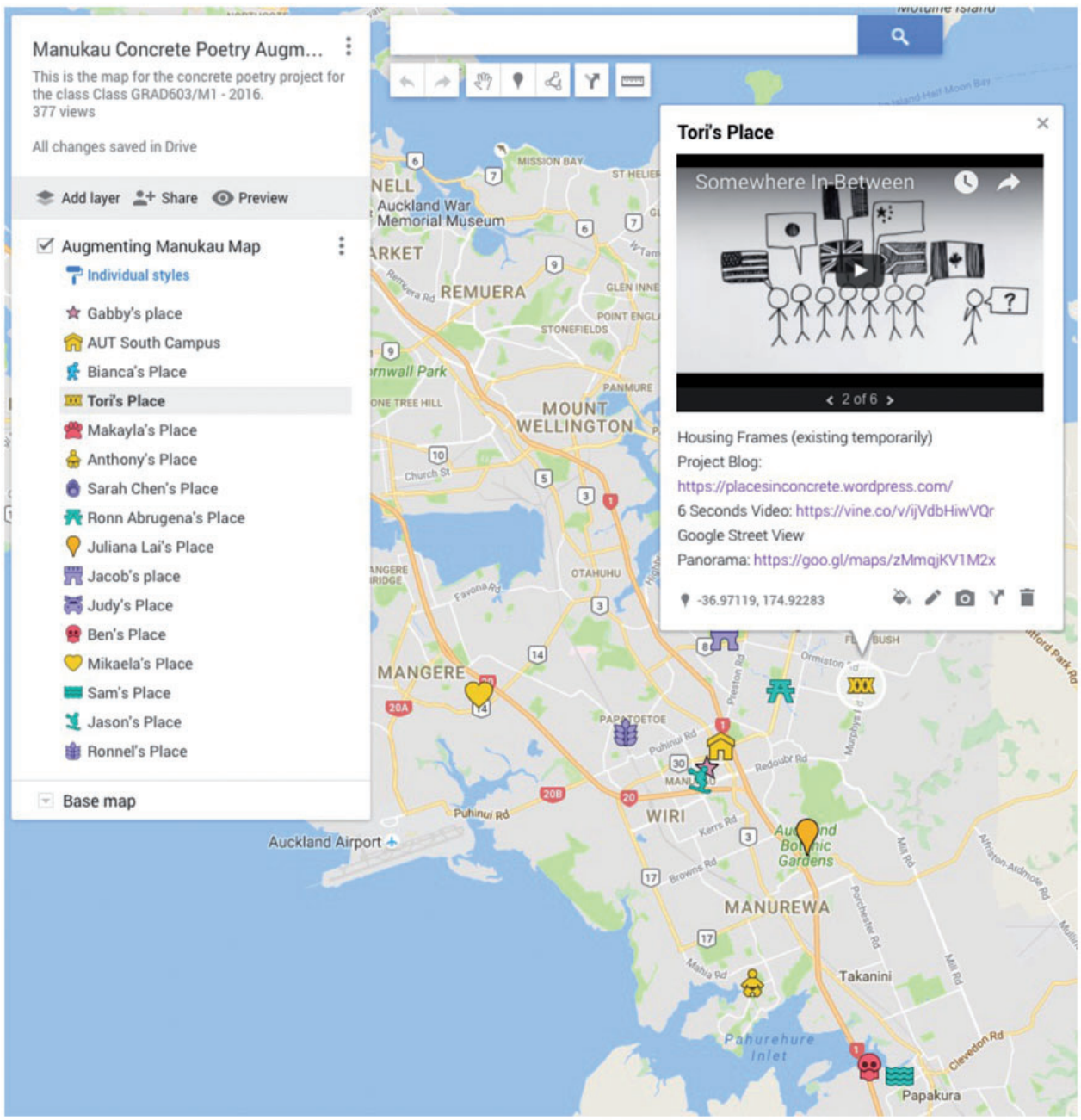

Figure 4. Collaborative Google map.

prototyping a new curriculum design based upon our developing framework. This second project iteration built more explicitly upon the work previously reported within an Art and Design elective in 2014 (Cochrane and Antonczak, 2015a, 2015b), that utilised a mobile social media ecology of resources to support the design of triggering events to enable students to reconceptualise their roles as active members of a professional global community. We began by surveying the students to establish their prior experiences.

Initial student survey 2017. At the beginning of the 2017 academic year we surveyed the 13 third-year students to capture their experiences based upon the 2016 project when the same cohort of students were second year students. The survey results are available at http:// bit.ly/2qOTbHz. The survey results reported that $54 \%$ of students defined themselves as 'digital natives', while the rest of the survey questions were designed to highlight those areas 


\section{Have you had any experience with Mobile Augmented Reality Apps?}

\section{Answered: 13 Skipped: 0}

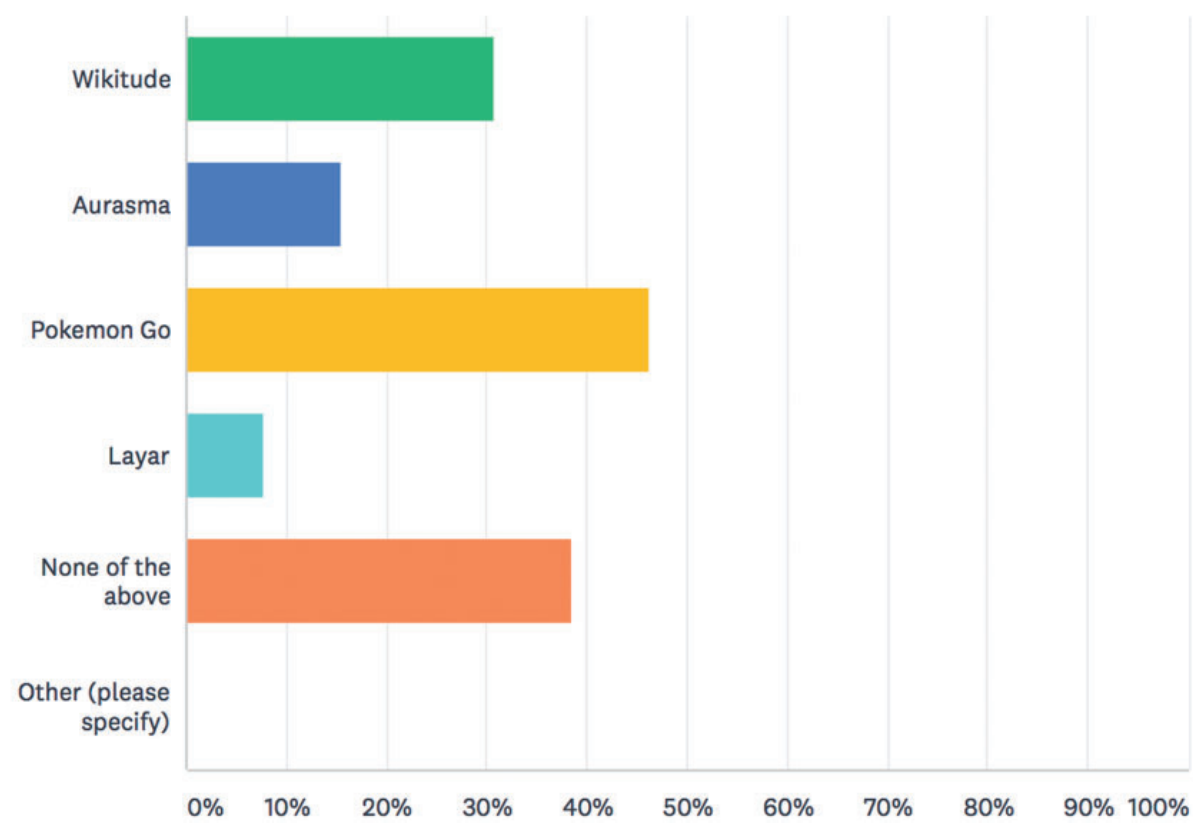

Figure 5. Students' prior mobile AR experience.

in which students had limited prior experience of mobile social media, illustrating that student competence with mobile social media lay within the confines of their prior experience comfort zones. All students owned multiple mobile devices, with iPhone and laptop ownership the highest tied at $69 \%$. Tablet ownership was the lowest category at $16 \%$ with an even split between the iPad and Android tablets. Student prior social media usage was dominated by Facebook's ecosystem, with 100\% Facebook users, and 77\% Instagram. Following this was YouTube viewing at 77\%, then Snapchat and Pinterest at $69 \%$ each. Wordpress use was high at $92 \%$ as this had been a requirement of their projects in year 2 . There was very little social media engagement reported beyond these. We were primarily interested in students' experience of mobile AR and VR, that were reported in the final two questions of the survey, shown in Figures 5 and 6.

Figure 5 shows that students reported very little experience of mobile AR and VR beyond Pokemon Go, which exhibited a short time frame of intense user interest and interaction in late 2016.

Figure 6 indicates that students' experience of mobile VR was limited to their Google Street View and collaborative custom Google Map 2016 project, where they were also introduced to Google Cardboard and the Samsung GearVR. This illustrates the relevance of the 'visitors and residents' metaphor (White and Le Cornu, 2011) rather than the 'digital native' myth (Helsper and Eynon, 2010; Smith and Western, 2012), whereby technology 


\section{Have you had any experience of mobile Virtual Reality?}

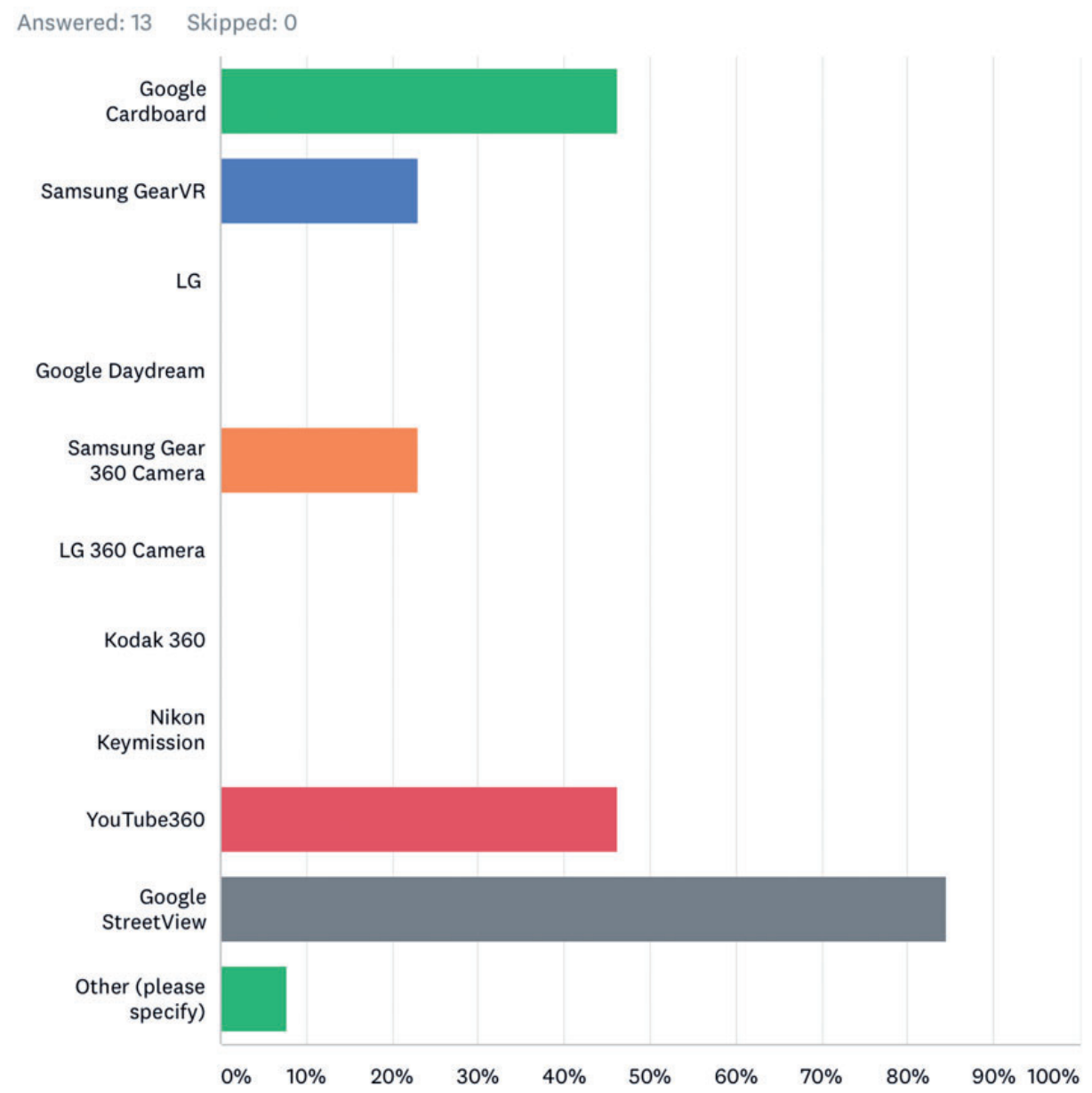

Figure 6. Students' prior mobile VR experience.

expertise is a function of regular use rather than the age of the user per se. The survey results provided us with a baseline of student prior experiences on which to build the integration of mobile AR and VR into the 2017 curriculum.

Redesigning the curriculum. The main difference from the project from 2016 was establishing how the creative market is changing and moving away from conventional methods of graphic design into new forms of collaborative teams sharing their work via new and emerging technology and how this can change the way designers think, produce and distribute their work.

Previously, the students' final work was required to be handed in on CD or DVD, but these distribution formats have now been superseded by online distribution. To update and redesign the student project distribution requirements we ran a series of workshops for the students exposing them to alternative methods of distribution and enhancement of viewer experiences via mobile AR and VR. Thus, students were introduced to a series of interactive 
workshops that invited them to explore and integrate mobile AR and VR into their own projects. Three workshops covered: 360 mobile video and imagery, creating and sharing interactive immersive environments using Seekbeak, creating and sharing interactive mobile 360 video via WondaVR. Student interaction in these workshops was curated via a social media hashtag \#360southside and archived in a Twitter 'Moment' at https://twitter.com/i/ moments/849359585970446336.

Hence, in 2017 we utilised an updated ecology of social media resources for enabling student-generated augmented reality. The choice of these tools was based upon the evaluation of mobile social media by the lecturer community of practice that continued throughout the teaching breaks between the 2016 academic year and 2017. This new ecology of resources encompassed the following:

- Student Wordpress blogs as reflective workbooks/journals, curated via Flipboard for formative feedback at https://flipboard.com/@davidsinfie2016/film-tiles-pdhfodkqy.

- A shared OneNote collaborative file-sharing environment.

- Student-created SeekBeak interactive AR/VR environments linking their various project artefacts (360 YouTube videos, Google Maps, 360 Streetview Panoramas, links to blog posts and Behance eportfolios, etc...).

- WondaVR to create and publish student-generated mobile VR App showcases of their work.

- A professional student eportfolio hosted on Behance, showcasing their final project works.

The updated ecology of resources for 2017 is illustrated in Figure 7.

The redesign of the student assessments focused upon augmenting traditional visual design projects with appropriate mobile AR and VR to enhance the viewer's experience and provide pathways for the artists/students to communicate the relevance and critical thinking behind their work. A comparison between the prior curriculum assessments for the third year course and the redesigned assessments are outlined in Table 1.

Examples of student work. Students were encouraged to link the various technologies that we explored together as a learning community to enhance and augment their physical artifacts. Students presented their projects to the entire class, their lecturer, and the researcher. For example, students used QR Codes and image-recognition mobile AR to link to and trigger the enhanced digital content associated with their physical posters (Figures 8 and 9).

Using various mobile AR applications, students enhanced their poster displays with a selection of digital content, triggering text popups, YouTube video playback, and audio narration of their concepts. Presentation of student projects were curated and shared with a potential global audience using a Twitter hashtag and video livestream using \#360southside and this was archived in a Twitter 'Moment' at https://twitter.com/i/moments/ 864618505303228418. Students also embedded and linked their work within their eportfolio Wordpress blogs, curated using Flipboard at https://flipboard.com/@davidsinfie2016/filmtiles-pdhfodkqy.

Examples of final student moving image projects can be seen at:

- Student 1 https://vimeo.com/219311860 


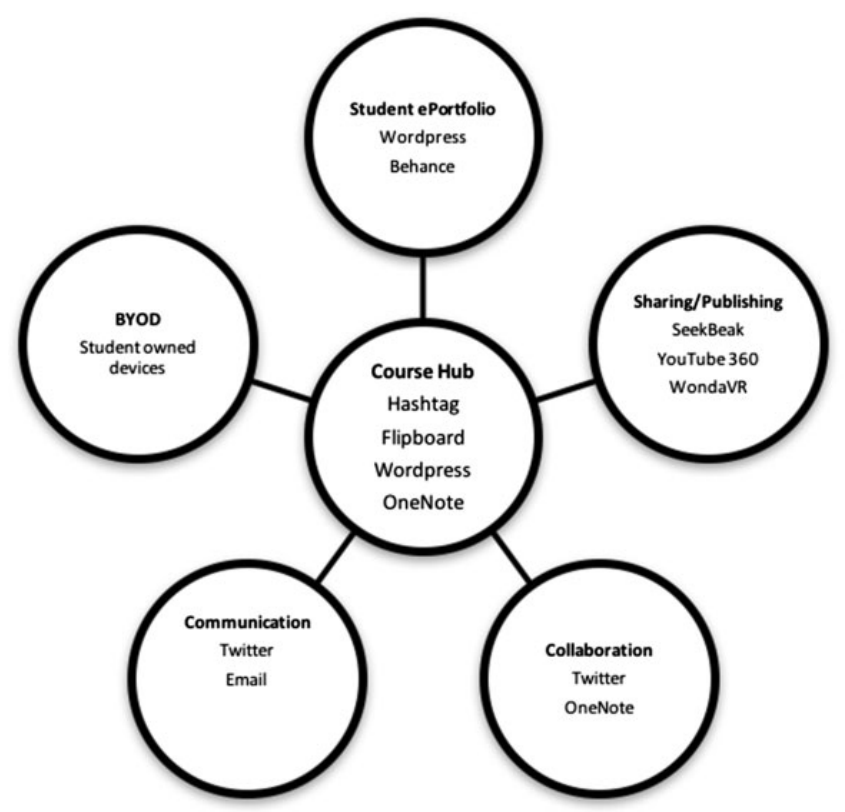

Figure 7. 2017 Ecology of resources.

Table I. Redesign of curriculum assessments.

\begin{tabular}{|c|c|}
\hline Original year 3 assessments & Redesigned year 3 assessments \\
\hline Design of personal logo and branding & $\begin{array}{l}\text { Design of animated interactive personal logo, shared } \\
\text { via YouTube or Vimeo }\end{array}$ \\
\hline Printed Poster & $\begin{array}{l}\text { Printed Poster enhanced with mobile AR and VR (for } \\
\text { example: QR Codes, Aurasma, Layar) }\end{array}$ \\
\hline Moving image sequence & $\begin{array}{l}\text { Moving image sequence with interactivity via } \\
\text { embedded hotspots (for example: using SeekBeak) }\end{array}$ \\
\hline $\begin{array}{l}\text { Application design of distribution } \\
\text { of final projects using DVD's and CD's }\end{array}$ & $\begin{array}{l}\text { Application design using either an online portfolio or } \\
\text { an App based ecosystem (for example: } \\
\text { Wonda VR) }\end{array}$ \\
\hline
\end{tabular}

- Student 2 https://www.youtube.com/watch?v=9ZGTwGtHcdw

- Student 3 https://vimeo.com/222119993

- Student 4 https://www.youtube.com/watch?v=X7wSvU-VuZw

Student feedback. Student feedback on the project was gathered via a SurveyMonkey survey after student grades for the project were returned. Survey data can be found at: https://www. surveymonkey.com/results/SM-R69DK3MH/.

All of the students reported using either Aurasma or Layar, or a combination of both, mobile AR applications to enhance their projects. They also explored and applied a variety of mobile VR applications from those that were introduced to them (Figure 10). 


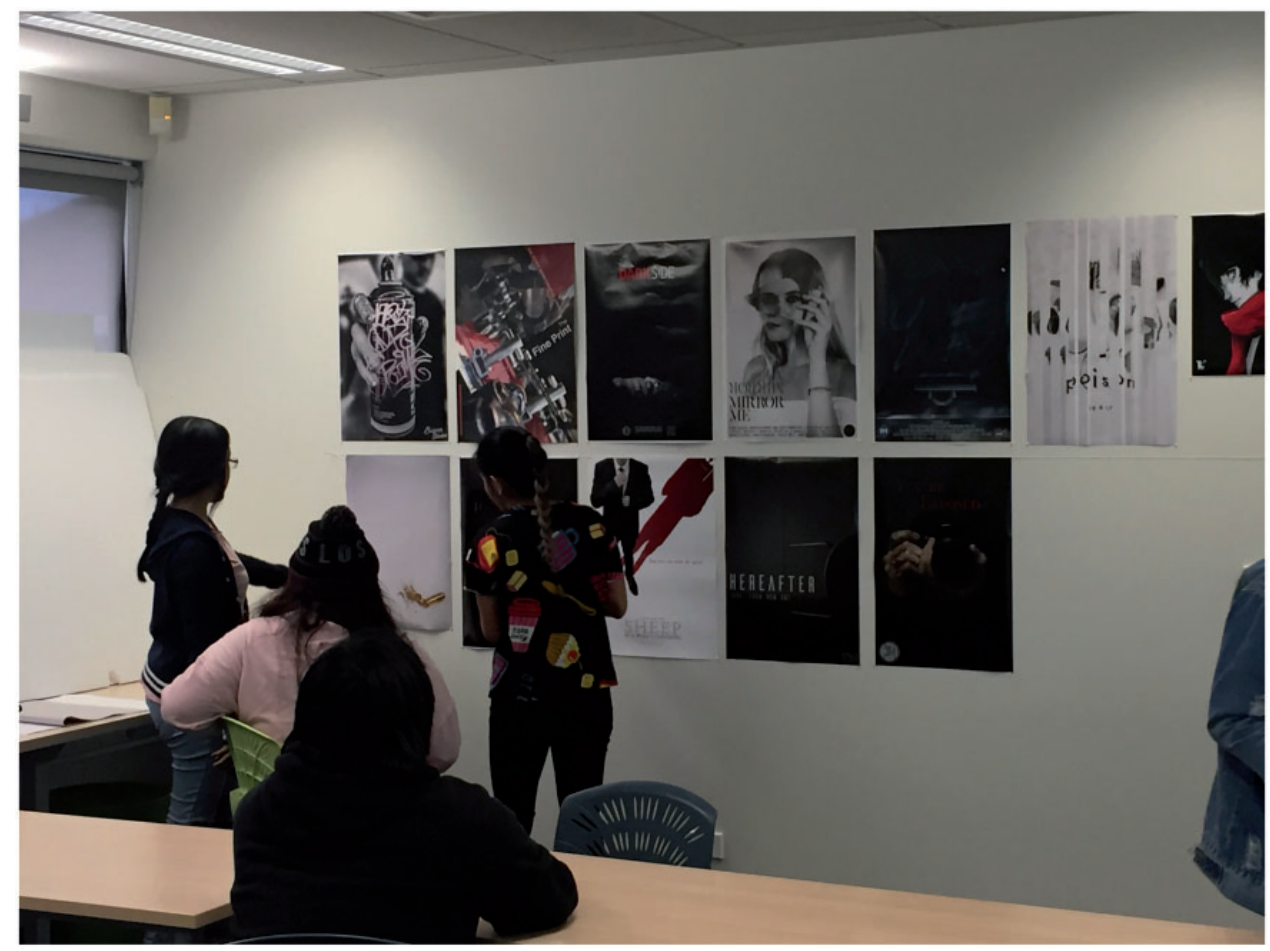

Figure 8. Display of augmented student posters.

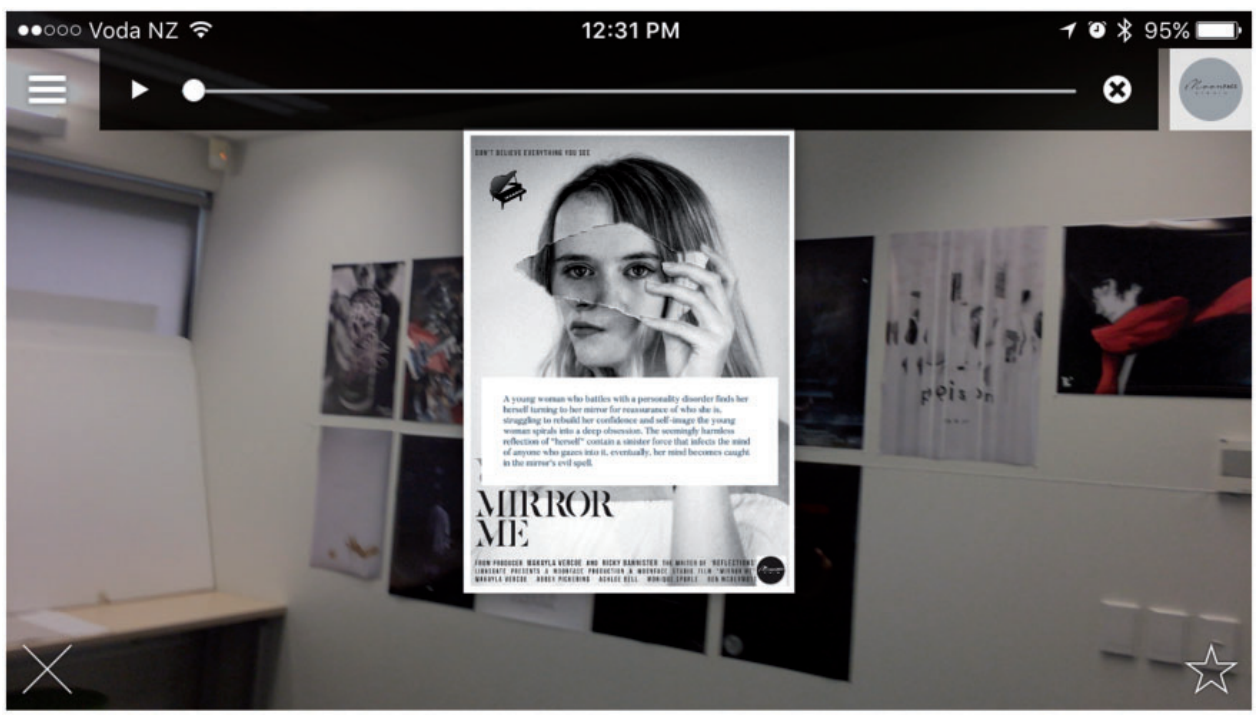

Figure 9. Mobile screenshot of Layar AR enhanced student poster. 
When responding to the question "What were the main benefits of enhancing your projects with mobile AR and VR?", students mentioned the new perspectives that these tools added to their work for their audience, added interactivity with their artwork, and deeper level of conceptualisation that these tools enabled. Several commented that the project added innovation and excitement to their work. Key issues that were raised by the students included the limitations of time to explore these new technologies, the limits of trial versions of the software, and designing for cross-platform compatibility across multiple types of user devices. Key themes that arose in response to the question "How do you plan to use mobile AR and VR in your future projects?" included:

\section{Q5}

\section{Which mobile Virtual Reality tools and platforms did you find most useful?}

\section{Answered: 12 Skipped: 0}

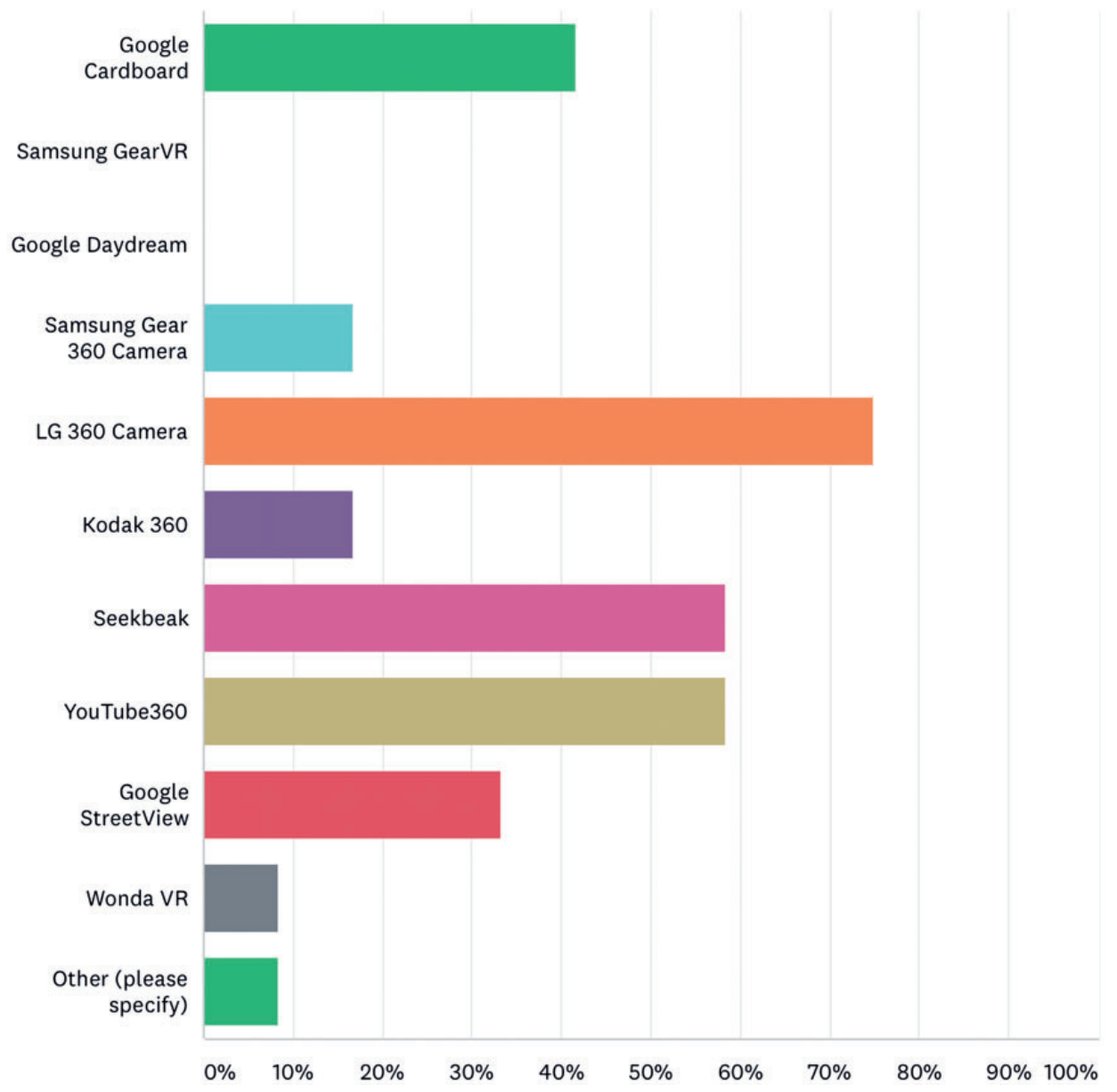

Figure 10. Mobile VR applications and tools used by students. 
I can use it to incorporate the AR and VR when I want to give the audience new perspective and different reality.

Adding a dynamic experience to still works (posters, books, etc) and to an event like the end of year exhibition.

\section{Discussion}

This paper has outlined the first two iterations of a curriculum redesign project guided by a design-based research methodology. We have argued and observed that augmenting graphic design education via mobile AR/VR technologies, while requiring a steep initial learning curve, facilitates the development of student creativity, and has enhanced their production of eportfolios of their work. In this section, we highlight the key reflections from our designbased research curriculum redesign project so far, and begin by revisiting our research questions.

\section{Revisiting our research questions}

- How can we design learning experiences that motivate graphic design students to critically explore new and emerging technologies, for example mobile augmented reality and virtual reality?

By critically exploring these technologies, students implemented creative ways to enhance the exhibition and impact of their physical graphic design installations. We scaffolded this process by beginning with simple social media AR/VR via an appropriate supporting ecology of resources such as Google Street view panoramas, YouTube 360 video, and SeekBeak, providing students with a conceptual framework on which to build the integration of these BYOD technologies into their projects. Utilising an DBR methodology to guide the design the curriculum redesign enabled the design of the project to be informed by literature and learning theories, cope with the inherent 'messiness' of mobile learning, integrate evaluation, provide authentic links to the local community, peer-reviewed feedback, and ultimately a critically redesigned curriculum.

- What assessment strategies can we use to highlight the potential of mobile AR and VR for showcasing student work to a much wider community audience beyond the physical classroom?

We redesigned the course assessment activities to integrate the exploration of the authentic use of AR and VR to enhance student projects. This ensured students explored the integration of new technologies into their work beyond the comfort zones of the more traditional graphic design technologies they were already comfortable with. Key implications of the mobile AR/VR augmentation project have been the need for both students and lecturers to upskill within these technology areas. Outcomes have enabled a redefinition of the concept of typography exhibitions and the ability to link to location-based contexts and share these with a wider audience beyond the classroom. 


\section{Curriculum design principles}

Our experiences with the graphic design curriculum redesign align with the curriculum design principles we have identified from similar projects in other higher education disciplines (Cochrane et al., 2017). These are summarised in the following principles:

- Begin with the graduate profile. What are the key skills and attributes required?

- Design mobile learning experiences that can effectively engage and challenge students to develop the required graduate capabilities.

- Lecturers must develop and model professional mobile and social media presence and profiles.

- Design triggering events that will stimulate student discussion and collaboration rather than delivery of content.

- Design an ecology of resources that supports the integration of mobile learning into the curriculum.

- Design authentic assessment activities that align the integration of mobile learning with the key graduate outcomes.

These curriculum design principles will be refined in the next iteration of our curriculum design project.

\section{Next stage of curriculum redesign}

What we have learnt so far is that simple forms of Augmented Reality and Virtual Reality such as interactive Google maps and immersive 360 degree video provide a feasible introductory tool for designing and sharing immersive project experiences beyond the confines of the studio or classroom. AR and VR enable our students to enhance their visual communication designs as they view and interact between the current state of the visual communication designs in the physical world and the possibility of adding to it but not necessarily replacing it via more immersive experiences. AR and VR are technologies that mediate ideas between humans and computers, humans and humans, and computers and humans, but require new design strategies. By using $\mathrm{AR}$ and VR as a mobile digital learning tool, we can enhance students' learning environments, design and integrate authentic learning projects within the curriculum that will prepare students for the rapidly changing profession of visual design.

\section{Limitations}

The main limitations of the project have been the emerging nature of the technologies - the limited availability of 360-degree video cameras and iBeacons in New Zealand to date. This has been the biggest challenge. In 2017, we purchased a small class set of 360 camera equipment (Kodak SP360 4K and four LG360 cams) for use with students' own mobile devices. The next stage of the project will be the refinement of design principles that have been identified through the initial stages of the project that can be used to guide other iterations of curriculum redesign integrating new and emerging technologies into student-lead projects. 


\section{Conclusion}

This paper explores the integration of new technologies within a traditionally face-to-face design studio learning environment to enhance and augment the limitations of a physical learning space. This curriculum redesign involved a collaboration between students, teachers, and educational researchers working together to explore and develop a collaborative ecology of resources to support new authentic learning environments. Our curriculum redesign was guided by utilising a design-based research methodology. The first stages of the curriculum redesign have led to the identification of design principles that can be refined in further iterations of the project.

\section{Declaration of Conflicting Interests}

The author(s) declared no potential conflicts of interest with respect to the research, authorship, and/or publication of this article.

\section{Funding}

The author(s) received no financial support for the research, authorship, and/or publication of this article.

\section{Notes}

1. Concrete poetry or 'Size' poetry is poetry in which the typographical arrangement of words is as important in conveying the intended effect as the conventional elements of the poem, such as meaning of words, rhythm, rhyme and so on. It is sometimes referred to as visual poetry, a term that has evolved to have distinct meaning of its own, but which shares the distinction of being poetry in which the visual elements are as important as the text.

2. The word Koha comes from the Māori tradition of gift and reflects the mana (respect) of giver and recipient.

\section{ORCID iD}

Thomas Cochrane (D) http://orcid.org/0000-0002-0192-6118

\section{References}

Balsamo A (2011) Designing Culture: The Technological Imagination at Work. Durham, USA: Duke University Press.

Bandura A (1986) Social Foundations of Thought and Action. Englewood Cliffs, NJ: Prentice-Hall.

Barab S and Squire K (2004) Design-based research: putting a stake in the ground. Journal of the Learning Sciences 13(1): 1-14.

Barnett R (2012) Learning for an unknown future. Higher Education Research \& Development 31(1): 65-77.

Beetham H and White D (2014) Students' expectations and experiences of the digital environment. Available at: www.jisc.ac.uk/blog/students-experiences-and-expectations-of-the-digital-environ ment-23-jun-2014 (accessed 18 April 2018).

Bower M, Howe C, McCredie N, et al. (2014) Augmented reality in education - Cases, places and potentials. Educational Media International 51(1): 1-15.

Boyer E (1990) Scholarship Reconsidered: Priorities of the Professoriate. Princeton, NJ: Carnegie Foundation for the Advancement of Teaching. 
Brown JS (2006) New learning environments for the 21st century: Exploring the edge. Change: The Magazine of Higher Learning 38(5): 18-24.

Bruner J (1966) Toward a Theory of Instruction. Cambridge: Belknap Press of Harvard University.

Buchem I, Cochrane, T, Gordon A, et al. (2012) Mlearning 2.0: The potential and challenges of collaborative mobile learning in participatory curriculum development in higher Education. In: Sánchez IA and Isaias P (eds) Proceedings of the IADIS international conference on mobile learning 2012, pp. 311-314. Berlin, Germany: IADIS International Association for Development of the Information Society.

Cochrane T (2016) Mobile VR in education: From the fringe to the mainstream. International Journal of Mobile and Blended Learning (IJMBL) 8(4): 45-61.

Cochrane T, Antonczak TL, Keegan H, et al. (2014) Riding the wave of BYOD: Developing a framework for creative pedagogies. Research in Learning Technology 22: 1-14.

Cochrane T, Antonczak L and Guinibert M (2014) Designing transformative learning environments. In: Rhetoric and reality: Critical perspectives on educational technology, the 31 st ascilite conference, Otago University, Dunedin, 24-26 November.

Cochrane T, Narayan V and Antonczak L (2015) Designing collaborative learning environments using mobile AR. In: EdMedia: World conference on educational media and technology 2015, Montreal, Quebec, Canada, 22-24 June.

Cochrane T and Antonczak L (2015a) Connecting the theory and practice of mobile learning: A framework for creative pedagogies using mobile social media. Media Education 6(2): 248-269.

Cochrane T and Antonczak L (2015b) Designing creative learning environments. Interaction Design and Architecture (s) Journal - IxD\&A 24: 125-144.

Cochrane T., Narayan V., and Antonczak L. (2016) A framework for designing collaborative learning environments using mobile AR. Journal of Interactive Learning Research. 27(4): 293-316.

Cochrane T, Sissons H and Mulrennan D (2017) Mainstreaming mobile learning in journalism education. In: H Crompton and J Traxler (eds) Mobile Learning in Higher Education: Challenges in Context. New York: Routledge, pp. 19-30.

Cook F (2016). Global tech leaders to convene in Auckland. NZ Herald, 29 April. Available at: www. nzherald.co.nz/business/news/article.cfm?c_id=3\&objectid=11630474 (accessed 18 April 2018).

Cook J (2010) Mobile phones as mediating tools within augmented contexts for development. International Journal of Mobile and Blended Learning 2(3): 1-12.

Cook J, Pachler N and Bachmair B (2013) Using social network sites and mobile technology to scaffold equity of access to cultural resources. In: $M$ Repetto and $G$ Trentin (eds) Using Network and Mobile Technology to Bridge Formal and Informal Learning. 10 ed. Oxford: Chandos Publishing, pp. 31-56.

Cook J and Santos P (2016) Three phases of mobile learning state of the art and case of mobile help seeking tool for the health care sector. In: D Churchill, J Lu, TKF Chiu, et al. (eds) Mobile Learning Design. Singapore: Springer Singapore, pp. 315-333.

Collins A (1999) The changing infrastructure of education research. In E. C. Lagemann \& L. S. Shulman (Eds.), Issues in Education Research: Problems and Possibilities (pp. 289-298). San Francisco, CA: Jossey-Bass.

Cormier D (2008) Rhizomatic education: Community as curriculum. Innovate 4(5). Available at: http://davecormier.com/edblog/2008/2006/2003/rhizomatic-education-community-as-curriculum/ (accessed 18 April 2018).

Dahlstrom E, Brooks C, Grajek S, et al. (2015) ECAR study of undergraduate students and information technology, 2015. Available at: www.educause.edu/library/resources/2015-student-and-fac ulty-technology-research-studies (accessed 18 April 2018).

Delello JA, McWhorter RR and Camp KM (2015) Integrating augmented reality in higher education: A multidisciplinary study of student perceptions. Journal of Educational Multimedia and Hypermedia 24(3): 209-233. 
Emin-Martinez V, Hansen C, Rodríguez-Triana MJS, et al. (2014) Towards teacher-led design inquiry of learning. eLearning Papers, 36: 1-12.

FitzGerald E, Ferguson R, Adams A, et al. (2013) Augmented reality and mobile learning: The state. International Journal of Mobile and Blended Learning 5(4): 43-58.

Frielick S and Whitehead E (2017). Learners and mobile devices: Learner survey conclusions. Available at: http://mobilelearners.nz/learners-and-mobile-devices/conclusion?path=learner-survey (accessed 18 April 2018).

Garnett F and Ecclesfield N (2008) Developing an organisational architecture of participation. British Journal of Educational Technology 39(3): 468-474.

Gibson I (2008) Preparing teachers for the future: A systemic approach to addressing 21st century educational imperatives. In: K McFerrin, et al. (eds) Proceedings of society for information technology \& teacher education international conference, pp. 4135-4142. Chesapeake, VA: AACE.

Hase S and Kenyon C (2007) Heutagogy: A child of complexity theory. Complicity: An International Journal of Complexity and Education 4(1): 111-118.

Helsper EJ and Eynon R (2010) Digital natives: Where is the evidence? British Educational Research Journal 36(3): 503-520.

Herrington A and Herrington J (eds) (2006) Authentic Learning Environments in Higher Education. Hershy: Information Science Publishing. 1-337

Herrington J, Herrington A, Mantei J, et al. (2009) New technologies, new pedagogies: Using mobile technologies to create new ways of teaching and learning - Final report to ALTC. Available at: https://www.academia.edu/178871/New_technologies_new_pedagogies_Using_mobile_teachnolo gies_to_create_new_ways_of_teaching_and_learning_-_Final_report_to_ALTC (accessed 28 April 2018).

Hollis R (2001) Graphic Design: A Concise History. London: Thames \& Hudson.

International Telecommunication Union (2015) The world in 2015: ICT facts and figures. Available at: www.itu.int/en/ITU-D/Statistics/Documents/facts/ICTFactsFigures2015.pdf (accessed 18 April 2018).

Kidd SH and Crompton H (2016) Augmented learning with augmented reality. In: D Churchill, J Lu, KFT Chiu, et al. (eds) Mobile Learning Design: Theories and Application. Singapore: Springer Singapore, pp. 97-108.

Lalwani M (2015) ABC News introduces VR initiative with 360-degree tour of Syria. Available at: www.engadget.com/2015/09/17/abc-news-introduces-vr-initiative-with-360-degree-tour-of-syria/ (accessed 18 April 2018).

Laurillard D (2001) Rethinking University Teaching: A framework for the Effective Use of Educational Technology. 2nd ed. London: Routledge.

Laurillard D (2008) Technology enhanced learning as a tool for pedagogical innovation. Journal of Philosophy of Education 42(3-4): 521-533.

Laurillard D (2012) Teaching as a Design Science: Building Pedagogical Patterns for Learning and Technology. New York: Routledge.

Laurillard D, Charlton P, Craft B, et al. (2013) A constructionist learning environment for teachers to model learning designs. Journal of Computer Assisted Learning 29(1): 15-30.

Luckin R (2008) The learner centric ecology of resources: A framework for using technology to scaffold learning. Computers \& Education 50(2): 449-462.

McKenney S and Reeves T (2012) Conducting Educational Design Research. London: Routledge.

Munari B (2008) Design as Art. London: Penguin Books.

Munnerley D, Bacon M, Fitzgerald R, et al. (2014) Augmented Reality: Application in Higher Education. Canberra, Australia: Australian Government Office for Learning and Teaching.

OECD (2015) Students, Computers and Learning. Pisa: OECD Publishing.

Ott M and Freina L (2015) A literature review on immersive virtual reality in education: State of the art and perspectives. In: Conference proceedings of eLearning and Software for Education (eLSE), No. 1, pp. 133-141. Romania: Universitatea Nationala de Aparare Carol I. 
Pachler N, Bachmair B and Cook J (2010) Mobile Learning: Structures, Agency, Practices. London: Springer.

Parsons D (2013) Jam today - Embedding BYOD into classroom practice. QScience Proceedings 2013(3): 25.

Puentedura R (2011) Thinking about change in learning and technology. In: 1st global mobile learning conference, Al Ain, UAE. Available at: www.hippasus.com/rrpweblog/archives/2012/04/10/iPad_ Intro.pdf (accessed 18 April 2018).

Santos IM (2013) Key challenges associated with bringing personal mobile devices to the classroom. QScience Proceedings 2013(3): 16.

Sinfield D (2013) Graphic design in a digital world: Enhancing graphic design teaching through digital technologies. International Journal of Design Education 7(1): 68-75.

Sinfield D, Cochrane T and Steagall M (2017). Augmented reality: Connecting the classroom and the community. In: THETA2017: Connecting minds, creating the future, Auckland, New Zealand, 710 May.

Smith JZS and Western M (2012) Beneath the 'Digital Native' myth: Understanding young Australians' online time use. Journal of Sociology 49(1): 97-118.

Somaiya R (2015) The Times partners with Google on virtual reality project. Available at: www. nytimes.com/2015/10/21/business/media/the-times-partners-with-google-on-virtual-reality-project. html?smid $=$ tw-nytimestech\&smtyp $=$ cur\&_r $=1$ (accessed 18 April 2018).

Spinoza B (1959) Spinoza's Ethics: And on the Correction of the Understanding, trans. A. Boyle, London: Everyman's Library.

Steagall M, Sinfield D, Cochrane T, et al. (2016). Contextualising the classroom: Using Google Maps and 360 degree imagery to augment the undergraduate design environment. In: ICERI2016 proceedings: the 9 th annual international conference of education, research and innovation, Seville, Spain, 14-16 November.

Sweeney J (2012) BYOD in education: A report for Australia and New Zealand. Available at: https:// cpb-ap-se2.wpmucdn.com/global2.vic.edu.au/dist/1/30307/files/2013/07/BYOD_DELL-2dtch9k. pdf (accessed 28 April, 2018).

Traxler J (2010) Will student devices deliver innovation, inclusion, and transformation. Journal of the Research Center for Educational Technology (RCET) 6(1): 3-15.

Wang F and Hannafin MJ (2005) Design-based research and technology-enhanced learning environments. Educational Technology Research and Development 53(4): 5-23. 1

Weaver D, Robbie D, Kokonis S, et al. (2012) Collaborative scholarship as a means of improving both university teaching practice and research capability. International Journal for Academic Development 18(3): 237-250.

White DS and Le Cornu A (2011) Visitors and residents: A new typology for online engagement. First Monday 16(9): 1-6.

Yang JN (2015) World's first virtual reality art exhibition with Tilt Brush. Available at: https:// virtualrealityreporter.com/tilt-brush-virtual-reality-painting-art-exhibition-world-first/ (accessed 18 April 2018).

\section{Author Biographies}

David Sinfield is a senior lecturer and programme director at Auckland University of Technology, New Zealand. He has created a new undergraduate programme that captured the aspects of Graphic Design, Moving Image and new technologies, such as mobile devices, AR and VR integrated within the undergraduate programme. In 2015 he was awarded the Vice Chancellor's teaching excellence awards at AUT. He has worked in the field of Graphic Design and Visual Communications (specialising in typographic design and moving image) for over thirty years both nationally and internationally. 
Thomas Cochrane is an academic advisor and senior lecturer in Educational Technology at Auckland University of Technology's Centre for Learning and Teaching (CfLAT). Thomas has expertise in Qualitative research in technology enhanced learning, with a focus upon action research, and design based research methodologies. His specialisations include mobile learning, heutagogy, communities of practice, and the scholarship of technology enhanced learning. His research portfolio includes 46 peer reviewed journal articles, 26 book chapters, and over 120 conference proceedings. 


\section{University Library}

\section{- M M I N E R VA A gateway to Melbourne's research publications}

Minerva Access is the Institutional Repository of The University of Melbourne

Author/s:

Sinfield, D;Cochrane, T

Title:

Augmenting visual design: Designing the changing classroom

Date:

2020-09-01

Citation:

Sinfield, D. \& Cochrane, T. (2020). Augmenting visual design: Designing the changing classroom. E-Learning and Digital Media, 17 (5), pp.365-387. https:// doi.org/10.1177/2042753018773769.

Persistent Link:

http://hdl.handle.net/11343/267519 